\title{
Predictors of unfavourable outcome in aneurysmal subarachnoid haemorrhage
}

\author{
Tijana Nastasovic ${ }^{1,2}$, Branko Milakovic ${ }^{1,2}$, Mila Stosic ${ }^{1}$, Jelena Eric Marinkovic ${ }^{2}$, Rosanda Ilic ${ }^{2,3}$, \\ Mihailo Milicevic ${ }^{2,3}$, Irena Cvrkota ${ }^{2,3}$, Kristina Radinovic $^{4}$, Olga Petrovic ${ }^{5}$, Danica Grujicic ${ }^{2,3}$ \\ ${ }^{1}$ Department of Anaesthesiology and Resuscitation on Clinic for Neurosurgery, Clinical Centre of Serbia, Belgrade, Serbia \\ ${ }^{2}$ School of Medicine, Belgrade, Serbia \\ ${ }^{3}$ Clinic for Neurosurgery, Clinical Centre of Serbia, Belgrade, Serbia
}

${ }^{4}$ Department of Anaesthesiology and Resuscitation on Clinic for Orthopaedic Surgery, Clinical Centre of Serbia, Belgrade, Serbia ${ }^{5}$ Clinic for Cardiology, Clinical Centre of Serbia, Belgrade, Serbia

\begin{abstract}
Background. Mortality rates following aneurysmal subarachnoid haemorrhage (aSAH) have decreased due to improvements in diagnoses and the management of complications, as well as early obliteration of the aneurysms. Neurogenic pulmonary oedema (NPO) is a clinical syndrome associated with an acute increase in intracranial pressure and a release of catecholamines into the circulation. This study investigated independent predictors of unfavourable outcomes (Glasgow Outcome Scores 1,2 or 3) in patients with aSAH. Materials and methods. A total of 262 patients with aSAH (162 females) were included in this prospective study. Clinical characteristics were assessed, and electrocardiographic, serum cardiac and inflammatory biomarker measurements were recorded on admission. Outcomes were assessed three months after admission. Univariate and multivariate analyses of these data were used to predict unfavourable outcomes.

Results. A total of 156 patients (59.54\%) had unfavourable outcomes. Compared to those who had favourable outcomes, patients with unfavourable outcomes were significantly older $(54.37 \pm 10.56$ vs. $49.13 \pm 10.77$ years; $p<0.001)$ and had more severe aSAHs (Hunt and Hess grades $\geq 3: 82.7 \%$ vs. $39.6 \% ; p<0.001)$. Patients with unfavourable outcomes were more likely to have NPO $(10.3 \%$ vs. $2.8 \% ; p=0.023)$, hydrocephalus ( $34.0 \%$ vs. $20.8 \% ; p=0.02)$, and aneurysm reruptures $(28.2 \%$ vs. $3.8 \% ; p<0.001)$. Independent predictors of an unfavourable outcome included Hunt and Hess grades $\geq 3$ (odds ratio [OR], 4.291; 95\% confidence interval [Cl], 2.168-8.491; $p<0.001$ ), increased systolic blood pressure on admission ( $O R, 1.020 ; 95 \% \mathrm{Cl}, 1.002-1.038 ; p=0.03)$, increased heart rate $(\mathrm{HR})$ on admission $(\mathrm{OR}, 1.024 ; 95 \% \mathrm{Cl}, 1.001-1.048 ; \mathrm{p}=0.04)$, and aneurysm rerupture $(\mathrm{OR}, 4.961 ; 95 \% \mathrm{Cl}, 1.461-16.845 ; \mathrm{p}=0.01)$. Conclusions. These findings suggest that aneurysm reruptures, as well as increased blood pressure and $\mathrm{HR}$, are associated with unfavourable outcomes in patients with aSAH.
\end{abstract}

Key words: subarachnoid hemorrhage, outcome, neurogenic pulmonary edema, hydrocephalus, rerupture (Neurol Neurochir Pol 2019; 53 (6): 421-427)

\section{Introduction}

Aneurysmal subarachnoid haemorrhage (aSAH) predominantly affects young adults and results in premature death in approximately $40 \%$ of patients [11,30,38]. Survivors often require help with daily living [1]. Neurogenic pulmonary oedema (NPO) is a clinical syndrome associated with an acute increase in intracranial pressure and a release of catecholamines into the circulation. After traumatic brain injury, aSAH is the second most common cause of NPO $[2,6,28]$. Patients with aSAH who develop NPO have higher mortality rates than those who do not $[17,28,35]$. Hypertension (HTA) is the most common comorbid disease, with prevalence estimates exceeding $40 \%$ in some studies $[18,20,41,42]$. No clear

Address for correspondence: Tijana Nastasovic, Clinical Centre of Serbia, Belgrade, Department of Anaesthesiology and Resuscitation on Clinic for Neurosurgery, Pasterova 2, Belgrade, Serbia, e-mail: tijananas@ptt.rs 
association between a premorbid history of HTA and aSAH outcome has been established [10, 18-20, 23]. We investigated the effects of NPO, HTA and other clinical variables on outcomes in patients with aSAH.

\section{Materials and methods}

Between August 2009 and January 2014, 262 consecutive patients who were admitted to the neurosurgery clinic were enrolled in the study. The inclusion criteria for the study were patients $\geq 18$ years of age with an aSAH diagnosis confirmed using cerebral computed tomography (CT) scanning and CT angiography [24]. If the $\mathrm{CT}$ angiogram was negative but the suspicion of an aneurysm was high, CT angiography was repeated two days later. The time interval between aSAH onset and hospital admission was $<96 \mathrm{~h}$. Chest X-rays of patients with suspected aSAH were obtained immediately. Patients with a history of myocardial infarction, cardiomyopathy or congestive heart failure were excluded from the study.

The study protocol was approved by the ethics committee of the School of Medicine, University of Belgrade (Belgrade, Serbia; no. 440/VI-11); informed consent was obtained from each patient or an appropriate designee. The identities of the patients were protected. All procedures were performed in accordance with relevant institutional guidelines and regulations. After enrolment, demographic and clinical data were collected by interviewing patients and their families and by reviewing medical records. These data included age, sex and risk factors for coronary artery disease. Heart rate (HR) and systolic blood pressure (SBP) measurements were recorded on admission. Neurological injuries were assessed for severity using the Hunt and Hess [12] and Fisher grades [7] recorded for each patient on admission. Patients classified as having Hunt and Hess grade I or II haemorrhages were admitted to the neurosurgery ward, whereas those with haemorrhages that were graded III-V were admitted to the neurosurgical intensive care unit (NICU).

\section{Clinical management}

For each patient, outcomes were determined three months after aSAH using the Glasgow Outcome Score (GOS) scale: 1 = death; 2 = persistent vegetative state; 3 = severe disability, conscious but disabled, dependent on others for daily support; $4=$ moderate disability, disabled but independent, can work in a sheltered setting; and $5=$ good recovery, resumption of normal daily living with minor deficits [16].

Patients with a GOS of 1, 2 or 3 were classified as having unfavourable outcomes, whereas those with a GOS of 4 or 5 were classified as having favourable outcomes.

Each patient was examined daily for signs of NPO using the clinical criteria described by Davison et al. [6], including abrupt respiratory distress (tachypnoea, dyspnoea or hypoxia $\left.\left[\mathrm{PaO}_{2} / \mathrm{FiO}_{2}<200\right]\right)$, the presence of bilateral crackles on auscultation, and the presence of frothy pink tracheal fluid. The radiographic criteria used to diagnose NPO included sharply defined bilateral pulmonary markings accompanied by blurring or haziness of the perivascular outlines and a loss of hilar shadow demarcation [28]. All chest X-rays were interpreted by board-certified radiologists who were blinded to the patients' clinical symptoms. The spontaneous resolution of pulmonary infiltrates occurred within $48 \mathrm{~h}$. Patients who fulfilled all of these criteria were diagnosed with NPO. Arterial blood gas analyses were used to determine the type of respiratory support necessary. If inotropic or vasopressor support was necessary, we recorded when this was initiated. All NICU patients were monitored continuously using electrocardiography (ECG) and by recording noninvasive blood pressure measurements in accordance with standard clinical practice. Central venous catheters, but not pulmonary artery catheters, were used [11].

All procedures were performed in accordance with the relevant aSAH treatment guidelines and recommendations $[4,37,38]$.

\section{Electrocardiographic, serum cardiac and inflammatory biomarkers}

Twelve-channel ECG was used on the day of each patient's enrolment to measure ST-T changes (e.g. ST depression or elevation, negative, biphasic or flattened $\mathrm{T}$ waves), the corrected Q-T wave (QTc) interval, rhythm disturbances and ventricular premature complexes. All electrocardiographic measurements were interpreted by board-certified cardiologists.

The following biomarkers for cardiac injury and inflammation were measured: creatine phosphokinase (CPK), CPK muscle/brain isoenzyme (CPK-MB), cardiac troponin I (TnI), and C-reactive protein (CRP). Total serum CPK and CPK-MB isoenzyme activities were measured using standard spectrophotometry. Serum TnI levels were measured using a chemiluminescence enzyme immunoassay. CRP was measured using turbidimetry. Biomarker levels were classified as elevated if they exceeded the following reference levels: CPK, $150 \mathrm{IU} / \mathrm{L}$ for women and $200 \mathrm{IU} / \mathrm{L}$ for men; CPK-MB, $24 \mathrm{IU} / \mathrm{L}$; TnI, $0.04 \mathrm{ng} / \mathrm{mL}$; and CRP, $5 \mathrm{mg} / \mathrm{L}$. The time interval between the onset of aSAH symptoms and biomarker measurements was less than $96 \mathrm{~h}$ for every patient.

\section{Neurological assessments}

Every patient was neurologically assessed and clinical signs of hydrocephalus, delayed cerebral ischaemia (DCI) and aneurysm reruptures were recorded. CT scans were also performed if there were signs of neurological deterioration. The term 'vasospasm' is used for narrowing of the large cerebral arteries and DCI caused by cerebral infarction and/or neurological deterioration. The criteria for aneurysm rerupture were new clinical signs of neurological deterioration together with signs of new bleeding on a CT scan. 
We only used clinical and radiological criteria (CT scans) to diagnose DCI and did not prove that this was due to vasospasm. Therefore, this data was not included in our analyses.

\section{Statistical analyses}

A total of 262 patients were dichotomised based on their three-month outcomes (unfavourable, GOS $=1-3$ or favourable, GOS = 4-5). Categorical variables were expressed as frequencies and percentages, whereas continuous variables were expressed as means \pm standard deviations. The Kolmogorov-Smirnov test was used to confirm that the data was normally distributed. For the unfavourable versus favourable group comparisons, chi-square and Fisher's exact tests were used for categorical variables, whereas unpaired $t$-tests and Mann-Whitney $U$ tests were used for continuous variables. Univariate and multivariate logistic regression analyses were used to identify variables that predicted unfavourable outcomes. The data was analysed using SPSS software (ver. 22.0; IBM Corp., Armonk, NY, USA); a p-value $<0.05$ was considered statistically significant.

\section{Results}

This study included 262 patients of whom 59.54\% (156 patients) had unfavourable outcomes. A total of 368 patients with aSAH were assessed, and 106 patients (28.8\%) were excluded. The reasons for exclusion were: 54 patients were admitted to hospital more than $96 \mathrm{~h}$ after aSAH onset, and 21, 16 and 15 patients had a history of myocardial infarction, cardiomyopathy, and congestive heart failure, respectively.

The mean ages of the 156 patients with unfavourable outcomes and the 106 patients with favourable outcomes were 54.37 and 49.13 years, respectively ( $\mathrm{p}<0.001$; Tab. 1 ). A total of $63.5 \%$ of the patients with NPO were women, whereas $60.1 \%$ of the patients who did not have NPO were women $(\mathrm{p}=0.04)$. A history of HTA was more common among patients with NPO $(p=0.001)$. There were significantly more patients with Hunt and Hess grades $\geq 3$ among those with unfavourable outcomes than among those with favourable outcomes ( $p<0.001)$. A comparison of radiological characteristics revealed a significant increase in the incidence of NPO among patients with Fisher grades $>2(\mathrm{p}<0.001)$. In addition, the mean peak SBP and HR were significantly increased in patients with unfavourable outcomes ( $\mathrm{p}<0.001$ and 0.007 , respectively).

Electrocardiographic measurements showed that there were no significant differences in the ST-T or QTc interval between patients with favourable and unfavourable outcomes. It was not clear whether patients with unfavourable outcomes had more severe cardiac damage than patients with favourable outcomes. The mean CPK-MB levels were significantly increased in patients with unfavourable compared to those with favourable outcomes $(15.3 \pm 7.3$ vs. $13.5 \pm 6.6 \mathrm{IU} / \mathrm{L}$; $\mathrm{p}=0.04)$, but the mean $\operatorname{TnI}(0.246 \pm 0.870 v$ s. $0.219 \pm 0.822 \mathrm{ng} / \mathrm{mL}$;
$\mathrm{p}=\mathrm{NS})$ and CPK $(143.8 \pm 103.2$ vs. $132.6 \pm 93.2 \mathrm{IU} / \mathrm{L} ; \mathrm{p}=\mathrm{NS})$ levels were not. However, unfavourable outcomes were significantly more common among patients with elevated CPK levels (33.3\% vs. 20.8\%; $\mathrm{p}=0.03)$. Mean CRP levels were not significantly increased in patients with unfavourable compared to those with favourable outcomes $(6.56 \pm 6.40 \mathrm{vs} .5 .52$ $\pm 4.48 \mathrm{mg} / \mathrm{L} ; \mathrm{p}=\mathrm{NS}$ ).

The neurological assessments showed that aneurysm reruptures and hydrocephalus were significantly more common among patients with unfavourable compared to those with favourable outcomes ( $p=0.02$ and $<0.001$, respectively). Patients with favourable outcomes also had a significantly increased frequency of secured aneurysms $(\mathrm{p}<0.001)$.

The GOSs of patients with aSAH showed that 36 patients (13.7\%) recovered well, 32 (12.2\%) had moderate disability, $83(31.7 \%)$ had severe disability, $71(27.1 \%)$ were in a persistent vegetative state, and 36 patients (13.7\%) died. After univariate logistic regression analysis and adjustment using multivariate logistic regression (Tab. 2), we identified the following independent predictors of unfavourable outcomes: Hunt and Hess grades $\geq 3$ (odds ratio [OR], 4.291 per quintile; $95 \%$ confidence interval [CI], 2.168-8.491; $\mathrm{p}<0.001)$, aneurysm reruptures (OR, 4.961; 95\% CI, 1.461-16.845; $\mathrm{p}=0.01$ ), increased SBP (OR, 1.020; 95\% CI, 1.002-1.038; $\mathrm{p}=0.03$ ), increased HR (OR, 1.024; 95\% CI, 1.001-1.048; $\mathrm{p}=0.04$ ), and unsecured aneurysms (OR, 9.377; 95\% CI, 1.138-77.244; p = 0.04).

\section{Discussion}

A comparison of demographic characteristics revealed that patients with unfavourable outcomes were significantly more likely to have had a severe haemorrhage (Hunt and Hess grades III-V) than patients with favourable outcomes (Tab. 1) $[17,28,35]$. In our cohort of 262 patients with aSAH, the incidence of unfavourable outcomes was $59.5 \%$. In a multicentre study performed by Galea et al. [9], 28.6\% of the patients had unfavourable outcomes. The difference between these studies may be due to patients in the multicentre study having a better neurological status on admission. In the multicentre study, the haemorrhage severity scores of almost $70 \%$ of patients were World Federation of Neurosurgeons grade I or II on admission, whereas in our study $35 \%$ of patients had a Hunt and Hess severity grade of I or II. All patients with unfavourable outcomes had severe bleeding (Fisher grades III and IV) that was radiologically visible [47].

In contrast to previous studies, we did not find that a ruptured aneurysm in the posterior circulation was a risk factor for unfavourable outcomes [14, 28, 31]. If patients in this category died before they reached hospital, this may explain why we did not observe a significant effect. Previous studies have also described electrocardiographic abnormalities and myocardial enzyme release in patients with aSAH $[3,29,39]$, but the effect of cardiac dysfunction on aSAH outcome remains unclear. Serum cardiac biomarkers have been used to predict 
Table 1. Comparison of variables between aSAH patients with unfavourable and favourable outcomes

\begin{tabular}{|c|c|c|c|}
\hline & $\begin{array}{l}\text { Pts with unfavourable outcome } \\
\qquad N=156\end{array}$ & $\begin{array}{l}\text { Pts with favourable outcome } \\
\qquad N=106\end{array}$ & $\mathbf{P}^{\mathbf{b}}$ \\
\hline Age (mean $\pm S D), y$ & $54.37 \pm 10.56$ & $49.13 \pm 10.77$ & $<0.001^{\mathrm{a}}$ \\
\hline Female sex, n (\%) & $99(63.5)$ & $63(59.4)$ & NS \\
\hline \multicolumn{4}{|l|}{ Clinical characteristics } \\
\hline Hunt and Hess $\geq 3, \mathrm{n}(\%)$ & $129(82.7)$ & $42(39.6)$ & $<0.001^{\mathrm{a}}$ \\
\hline $\mathrm{SBP}($ mean $\pm \mathrm{SD}), \mathrm{mmHg}$ & $156.57 \pm 23.35$ & $137.36 \pm 21.28$ & $<0.001^{\mathrm{a}}$ \\
\hline $\mathrm{HR}($ mean $\pm \mathrm{SD}), \min ^{-1}$ & $84.29 \pm 16.96$ & $78.92 \pm 14.03$ & $0.007^{\mathrm{a}}$ \\
\hline Admission on day of aSAH attack, n (\%) & $72(55.8)$ & $57(53.8)$ & NS \\
\hline NPO, n (\%) & $16(10.3)$ & $3(2.8)$ & $0.02^{\mathrm{a}}$ \\
\hline \multicolumn{4}{|l|}{ Risk factors for $C A D, n$ (\%) } \\
\hline History of hypertension & $72(46.2)$ & $28(26.4)$ & $0.001^{\mathrm{a}}$ \\
\hline History of smoking & $31(19.9)$ & $35(33.0)$ & $0.02^{\mathrm{a}}$ \\
\hline History of diabetes & $27(17.3)$ & $19(17.9)$ & NS \\
\hline History of hyperlipidemia & $44(28.2)$ & $33(31.1)$ & NS \\
\hline Family history of CAD & $42(26.9)$ & $26(24.5)$ & NS \\
\hline \multicolumn{4}{|l|}{ Radiological characteristics } \\
\hline Fisher > 2, n (\%) & $123(78.8)$ & $47(44.3)$ & $<0.001^{\mathrm{a}}$ \\
\hline Anterior circulation aneurysm location, n (\%) & $138(88.5)$ & $95(89.6)$ & NS \\
\hline Multiple aneurysms, n (\%) & $14(9.0)$ & $14(13.2)$ & NS \\
\hline \multicolumn{4}{|l|}{ ECG characteristics } \\
\hline ST-T changes, n (\%) & $41(26.3)$ & $23(21.7)$ & NS \\
\hline ST depression, $\mathrm{n}(\%)$ & $22(14.1)$ & $7(6.6)$ & NS \\
\hline ST elevation, $\mathrm{n}(\%)$ & $19(12.2)$ & $11(10.4)$ & NS \\
\hline Negative T waves, n (\%) & $14(9.0)$ & $10(9.4)$ & NS \\
\hline Prolonged QTc interval, n (\%) & $30(19.2)$ & $11(10.4)$ & NS \\
\hline Ventricular premature complexes, n (\%) & $14(9.0)$ & $10(9.4)$ & NS \\
\hline \multicolumn{4}{|l|}{ Neurological characteristics } \\
\hline Secured $^{\mathrm{c}}$ aneurysm, n (\%) & $109(69.9)$ & $105(99.1)$ & $<0.001 a$ \\
\hline Hydrocephalus, n (\%) & $53(34.0)$ & $22(20.8)$ & $0.02^{\mathrm{a}}$ \\
\hline Rerupture, $\mathrm{n}(\%)$ & $44(28.2)$ & $4(3.8)$ & $<0.001^{\mathrm{a}}$ \\
\hline Seizures, n (\%) & $30(19.2)$ & $23(21.7)$ & NS \\
\hline \multicolumn{4}{|l|}{ Biohumoral characteristics } \\
\hline Troponin I, (mean \pm SD), ng/mL, median (IQR) & $\begin{array}{c}0.246 \pm 0.870 \\
0.021(0.010-0.063)\end{array}$ & $\begin{array}{c}0.219 \pm 0.822 \\
0.020(0.011-0.054)\end{array}$ & NS \\
\hline Elevated troponin I, n (\%) & $50(32.1)$ & $32(30.2)$ & NS \\
\hline $\begin{array}{l}\mathrm{CPK}(\text { mean } \pm \mathrm{SD}), \mathrm{IU} / \mathrm{L}, \\
\text { median }(\mathrm{IQR})\end{array}$ & $\begin{array}{c}143.8 \pm 103.2 \\
112.0(68.5-213.0)\end{array}$ & $\begin{array}{c}132.6 \pm 93.2 \\
103.5(76.5-164.3)\end{array}$ & NS \\
\hline Elevated CPK, n (\%) & $52(33.3)$ & $22(20.8)$ & $0.03^{\mathrm{a}}$ \\
\hline $\begin{array}{l}\text { CPK-MB (mean } \pm S D), I U / L, \\
\text { median (IQR) }\end{array}$ & $\begin{array}{c}15.3 \pm 7.3 \\
14.0(10.0-2.0)\end{array}$ & $\begin{array}{c}13.5 \pm 6.6 \\
12.0(8.0-17.0)\end{array}$ & $0.04^{\mathrm{a}}$ \\
\hline Elevated CPK-MB, n (\%) & $18(11.5)$ & $9(8.5)$ & NS \\
\hline $\begin{array}{l}\text { C-reactive protein (mean } \pm \mathrm{SD} \text { ), } \mathrm{mg} / \mathrm{L} \\
\text { median }(\mathrm{IQR})\end{array}$ & $\begin{array}{c}6.56 \pm 6.40 \\
4.95(2.83-8.85)\end{array}$ & $\begin{array}{c}5.52 \pm 4.48 \\
4.55(2.88-6.95)\end{array}$ & NS \\
\hline Elevated C-reactive protein, $\mathrm{n}(\%)$ & $76(48.7)$ & $45(42.5)$ & NS \\
\hline
\end{tabular}

aSAH - aneurysmal subarachnoid haemorrhage; NPO — neurogenic pulmonary oedema; SBP — systolic blood pressure; HR — heart rate; CAD — coronary artery disease; ECG — electrocardiography; SD standard deviation; IQR — interquartile range; CPK — creatine phosphokinase; CPK-MB — creatine phosphokinase MB isoenzyme

${ }^{\text {s}}$ Statistically significant

${ }^{b}$ According to chi-square, Student's t-test or Mann-Whitney U test where appropriate

'All of 214 pts with secured aneurysm had aneurysm clipped, except three of them (all with unfavourable outcomes) whose aneurysms were coiled 
Table 2. Multivariate logistic regression analysis to identify variables predictive of unfavourable outcome associated with $\mathrm{ASAH}$

\begin{tabular}{lccc}
\multicolumn{1}{c}{ Predictor } & OR & Multivariate \\
\hline Age, years & $\mathbf{9 5 \%} \mathbf{C l}$ & $\mathbf{P}$ \\
Female sex & 1.030 & $0.999-1.063$ & NS \\
Hunt and Hess grade $\geq 3$ & $0.863-3.548$ & NS \\
History of HTA & 4.291 & $2.168-8.491$ & $<0.00^{\mathrm{a}}$ \\
History of smoking & 0.749 & $0.349-1.606$ & NS \\
NPO & 1.852 & $0.878-3.908$ & NS \\
SBP & 2.104 & $0.433-10.215$ & NS \\
HR & 1.020 & $1.002-1.038$ & $0.03^{\mathrm{a}}$ \\
Hydrocephalus & 1.024 & $1.001-1.048$ & $0.04^{\mathrm{a}}$ \\
Rerupture & 1.607 & $0.766-3.371$ & $\mathrm{NS}$ \\
Unsecured aneurysm & 4.961 & $1.461-16.845$ & $0.01^{\mathrm{a}}$ \\
Prolonged QTC & 9.377 & $1.138-77.244$ & $0.04^{\mathrm{a}}$ \\
CPK-MB (IU/L) & 0.757 & $0.266-2.154$ & NS
\end{tabular}

$\mathrm{Cl}$ - confidence interval; $\mathrm{OR}$ - odds ratio; aSAH - aneurysmal subarachnoid haemorrhage; $\mathrm{HTA}$ - hypertension; NPO - neurogenic pulmonary oedema; SBP — systolic blood pressure; $\mathrm{HR}$ - heart rate; CPK-MB - creatine phosphokinase MB isoenzyme ${ }^{\text {a }}$ Statistically significant

negative outcomes [21, 22, 25, 43, 44, 46]. In our study, only mean CPK-MB levels were significantly increased in patients with unfavourable outcomes. Univariate logistic regression analysis revealed that increased levels of CPK-MB could predict unfavourable outcomes. A meta-analysis by Zhang et al. [46] showed that an increase in TnI was associated with an increased risk of poor outcome (OR 1.85; 95\% CI 1.49-2.30).

In our study, electrocardiographic abnormalities did not occur more frequently in patients with unfavourable outcomes. A prolonged QTc interval did predict unfavourable outcomes in the univariate logistic regression analysis. However, neither of these variables was an independent predictor of unfavourable outcomes [13]. In many studies, NPO is associated with unfavourable outcomes $[17,28,36]$. However, in our study, NPO was not an independent predictor of unfavourable outcomes.

Multivariate logistic regression analysis revealed that Hunt and Hess grades, aneurysm reruptures, increased SBP and HR and unsecured aneurysms were independent predictors of unfavourable outcomes in patients with aSAH. Previous studies have shown that the only consistent and independent predictors of negative outcomes in aSAH patients are poor haemorrhage severity grades, older age, aneurysm reruptures, and DCI [27, 32, 33, 45].

Neurological status on admission to hospital reflects the severity of a brain injury at the time of rupture. This is the single most important predictor of outcomes in patients with aSAH [38, 45]. Jaja et al. [15] demonstrated that each one-point increase in neurological grade resulted in an approximately two-fold increase in the risk of a poor outcome at three months.

Many studies have shown that aneurysm rerupture is a strong predictor of outcomes in patients with aSAH [40].
Early treatment of a ruptured aneurysm is particularly important to reduce rebleeding [9]. In addition, an unsecured aneurysm, with or without rebleeding, is a predictor of poor outcomes in patients with aSAH because more aggressive measures (e.g. HTA and haemodilution therapy) can be used to prevent vasospasm in patients with a secured aneurysm.

In patients with aSAH, an association between $\mathrm{HTA}$ and outcomes has been supported by some studies $[6,18,19,34$, $42]$ and questioned by others $[6,10,20,23,26]$. De Marchis et al. [5] found that patients with premorbid HTA had more severe initial bleeding and an increased risk of mortality while in hospital. Our study found that increased SBP, but not premorbid HTA, was a predictor of negative outcomes.

Zheng et al. [48] also showed that good control of premorbid HTA had a favourable effect on outcomes in patients with aSAH. Patients with uncontrolled HTA had more severe aSAH and haemorrhage grades than patients with well-controlled HTA. In addition, the patients with uncontrolled HTA included more frequent cases of aneurysm rebleeding, hydrocephalus and cerebral vasospasm, even after adjustment for age and poor Hunt and Hess grade.

However, we found that a history of premorbid HTA was not a predictor of unfavourable outcomes in aSAH patients. Increased HR on admission was an independent predictor of negative outcomes. Schmidt et al. [36] showed that a prolonged elevated HR was associated with major adverse cardiopulmonary events and poor outcomes in aSAH patients.

This study has some limitations. Firstly, different time intervals between the onset of aSAH and hospital admission may have influenced our results. Secondly, we excluded patients with a history of myocardial infarction, congestive heart failure and cardiomyopathy to investigate the incidence of NPO in patients with aSAH. This may also have influenced our results. Finally, we only recorded measurements once and this was within $96 \mathrm{~h}$ of aSAH onset. In total, $50.8 \%$ of these measurements were recorded after the initiation of aSAH therapy. Despite these limitations, this is the only study to have investigated the spectrum of clinical, radiological and biochemical variables that may be used to predict negative outcomes in patients with aSAH. The influence of aSAH treatment on these results should be assessed in more detail.

\section{Conclusions}

In patients with aSAH, the predictors of unfavourable outcomes include a high Hunt and Hess grade, aneurysm rerupture, and an unsecured aneurysm, as well as increased SBP or HR. NPO and premorbid HTA are not independent predictors of unfavourable outcomes.

\section{Conflict of interest}

The authors declare that they have no conflict of interest. 
All procedures performed in studies involving human participants were in accordance with the ethical standards of the institutional and/or national research committee, and in accordance with the 1964 Helsinki Declaration and its later amendments or comparable ethical standards.

Informed consent was obtained from all individual participants included in the study.

This publication was prepared without any external source of funding.

\section{References}

1. Al-Khindi T, Macdonald RL, Schweizer TA, et al. Cognitive and functional outcome after aneurysmal subarachnoid hemorrhage. Stroke. 2010; 41(8): e519-e536, doi: 10.1161/STROKEAHA.110.581975, indexed in Pubmed: 20595669.

2. Bahloul M, Chaari AN, Kallel H, et al. Neurogenic pulmonary edema due to traumatic brain injury: evidence of cardiac dysfunction. Am J Crit Care. 2006; 15(5): 462-470, indexed in Pubmed: 16926367.

3. Brouwers PJ, Wijdicks EF, Hasan D, et al. Serial electrocardiographic recording in aneurysmal subarachnoid hemorrhage. Stroke. 1989; 20(9): 1162-1167, doi: 10.1161/01.str.20.9.1162, indexed in Pubmed: 2772976.

4. Connolly ES, Rabinstein AA, Carhuapoma JR, et al. American Heart Association Stroke Council, Council on Cardiovascular Radiology and Intervention, Council on Cardiovascular Nursing, Council on Cardiovascular Surgery and Anesthesia, Council on Clinical Cardiology. Guidelines for the management of aneurysmal subarachnoid hemorrhage: a guideline for healthcare professionals from the American Heart Association/american Stroke Association. Stroke. 2012; 43(6): 1711-1737, doi: 10.1161/STR.0b013e3182587839, indexed in Pubmed: 22556195.

5. De Marchis GM, Lantigua H, Schmidt JM, et al. Impact of premorbid hypertension on haemorrhage severity and aneurysm rebleeding risk after subarachnoid haemorrhage. J Neurol Neurosurg Psychiatry. 2014; 85(1): 56-59, doi: 10.1136/jnnp-2013-305051, indexed in Pubmed: 23813741.

6. Davison DL, Terek M, Chawla LS. Neurogenic pulmonary edema. Crit Care. 2012; 16(2): 212, doi: 10.1186/cc11226, indexed in Pubmed: 22429697.

7. Fisher CM, Kistler JP, Davis JM. Relation of cerebral vasospasm to subarachnoid hemorrhage visualized by computerized tomographic scanning. Neurosurgery. 1980; 6(1): 1-9, doi: 10.1227/00006123198001000-00001, indexed in Pubmed: 7354892.

8. Fontes RBV, Aguiar PH, Zanetti MV, et al. Acute neurogenic pulmonary edema: case reports and literature review. J Neurosurg Anesthesiol. 2003; 15(2): 144-150, indexed in Pubmed: 12658001.

9. Galea JP, Dulhanty L, Patel HC, et al. UK and Ireland Subarachnoid Hemorrhage Database Collaborators. Predictors of Outcome in Aneurysmal Subarachnoid Hemorrhage Patients: Observations From a Multicenter Data Set. Stroke. 2017; 48(11): 2958-2963, doi: 10.1161/ STROKEAHA.117.017777, indexed in Pubmed: 28974630.

10. Germanson TP, Lanzino G, Kongable GL, et al. Risk classification after aneurysmal subarachnoid hemorrhage. Surg Neurol. 1998; 49(2): 155-163, doi: 10.1016/s0090-3019(97)00337-6, indexed in Pubmed: 9457265.

11. Hop JW, Rinkel GJ, Algra A, et al. Case-fatality rates and functional outcome after subarachnoid hemorrhage: a systematic review. Stroke.
1997; 28(3): 660-664, doi: 10.1161/01.str.28.3.660, indexed in Pubmed: 9056628.

12. Hunt WE, Hess RM. Surgical risk as related to time of intervention in the repair of intracranial aneurysms. J Neurosurg. 1968; 28(1): 14-20, doi: 10.3171/jns.1968.28.1.0014, indexed in Pubmed: 5635959

13. Ichinomiya T, Terao Y, Miura K, et al. QTc interval and neurological outcomes in aneurysmal subarachnoid hemorrhage. Neurocrit Care. 2010; 13(3): 347-354, doi: 10.1007/s12028-010-9411-9, indexed in Pubmed: 20652444.

14. Inamasu J, Nakatsukasa M, Mayanagi K, et al. Subarachnoid hemorrhage complicated with neurogenic pulmonary edema and takotsubo-like cardiomyopathy. Neurol Med Chir (Tokyo). 2012; 52(2): 49-55, doi: 10.2176/nmc.52.49, indexed in Pubmed: 22362283.

15. Jaja BNR, Lingsma H, Schweizer TA, et al. SAHIT collaboration. Prognostic value of premorbid hypertension and neurological status in aneurysmal subarachnoid hemorrhage: pooled analyses of individual patient data in the SAHIT repository. J Neurosurg. 2015; 122(3): 644 652, doi: 10.3171/2014.10.JNS132694, indexed in Pubmed: 25554825.

16. Jennett B, Bond M. Assessment of outcome after severe brain damage Lancet. 1975; 1: 480-484.

17. Junttila E, Ala-Kokko T, Ohtonen P, et al. Neurogenic pulmonary edema in patients with nontraumatic intracerebral hemorrhage: predictors and association with outcome. Anesth Analg. 2013; 116(4): 855861, doi: 10.1213/ANE.0b013e3182811cc7, indexed in Pubmed: 23429802.

18. Juvela S. Prehemorrhage risk factors for fatal intracranial aneurysm rupture. Stroke. 2003; 34(8): 1852-1857, doi: 10.1161/01. STR.0000080380.56799.DD, indexed in Pubmed: 12829865.

19. Kassell NF, Torner JC, Haley EC, et al. The International Cooperative Study on the Timing of Aneurysm Surgery. Part 1: Overall management results. J Neurosurg. 1990; 73(1): 18-36, doi: 10.3171/ jns.1990.73.1.0018, indexed in Pubmed: 2191090.

20. Keller AZ. Hypertension, age and residence in the survival with subarachnoid hemorrhage. Am J Epidemiol. 1970; 91(2): 139-147, doi: 10.1093/oxfordjournals.aje.a121121, indexed in Pubmed: 5416247.

21. Kilbourn KJ, Ching G, Silverman DI, et al. Clinical outcomes after neurogenic stress induced cardiomyopathy in aneurysmal sub-arachnoid hemorrhage: a prospective cohort study. Clin Neurol Neurosurg. 2015; 128: 4-9, doi: 10.1016/j.clineuro.2014.10.017, indexed in Pubmed: 25462088.

22. Kilbourn KJ, Levy S, Staff I, et al. Clinical characteristics and outcomes of neurogenic stress cadiomyopathy in aneurysmal subarachnoid hemorrhage. Clin Neurol Neurosurg. 2013; 115(7): 909-914, doi: 10.1016/j.clineuro.2012.09.006, indexed in Pubmed: 23021080.

23. Le Roux PD, Elliott JP, Newell DW, et al. Predicting outcome in poor-grade patients with subarachnoid hemorrhage: a retrospective review of 159 aggressively managed cases. J Neurosurg. 1996; 85(1): 39-49, doi: 10.3171/jns.1996.85.1.0039, indexed in Pubmed: 8683281.

24. Menke J, Larsen J, Kallenberg K. Diagnosing cerebral aneurysms by computed tomographic angiography: meta-analysis. Ann Neurol. 2011; 69(4): 646-654, doi: 10.1002/ana.22270, indexed in Pubmed: 21391230

25. Milakovic B, Nastasovic T, Lepic M, et al. Takotsubo cardiomyopathy in aneurysmal subarachnoid hemorrhage: A case report. Vojnosanitetski pregled. 2017(00): 179-179, doi: 10.2298/vsp170705179m. 
26. Mocco J, Ransom ER, Komotar RJ, et al. Preoperative prediction of long-term outcome in poor-grade aneurysmal subarachnoid hemorrhage. Neurosurgery. 2006; 59(3): 529-38; discussion 529, doi: 10.1227/01.NEU.0000228680.22550.A2, indexed in Pubmed: 16955034.

27. Molyneux AJ, Kerr RSC, Yu LM, et al. International Subarachnoid Aneurysm Trial (ISAT) Collaborative Group. International subarachnoid aneurysm trial (ISAT) of neurosurgical clipping versus endovascular coiling in 2143 patients with ruptured intracranial aneurysms: a randomised comparison of effects on survival, dependency, seizures, rebleeding, subgroups, and aneurysm occlusion. Lancet. 2005; 366(9488): 809-817, doi: 10.1016/S0140-6736(05)67214-5, indexed in Pubmed: 16139655.

28. Muroi C, Keller M, Pangalu A, et al. Neurogenic pulmonary edema in patients with subarachnoid hemorrhage. J Neurosurg Anesthesiol. 2008; 20(3): 188-192, doi: 10.1097/ANA.0b013e3181778156, indexed in Pubmed: 18580349.

29. Naidech AM, Kreiter KT, Janjua N, et al. Cardiac troponin elevation, cardiovascular morbidity, and outcome after subarachnoid hemorrhage. Circulation. 2005; 112(18): 2851-2856, doi: 10.1161/CIRCULATIONAHA.105.533620, indexed in Pubmed: 16267258.

30. Nieuwkamp DJ, Setz LE, Algra A, et al. Changes in case fatality of aneurysmal subarachnoid haemorrhage over time, according to age, sex, and region: a meta-analysis. Lancet Neurol. 2009; 8(7): 635-642, doi: 10.1016/S1474-4422(09)70126-7, indexed in Pubmed: 19501022.

31. Ochiai H, Yamakawa Y, Kubota E. Deformation of the ventrolateral medulla oblongata by subarachnoid hemorrhage from ruptured vertebral artery aneurysms causes neurogenic pulmonary edema. Neurol Med Chir (Tokyo). 2001; 41(11): 529-34; discussion 534, doi: 10.2176/ nmc.41.529, indexed in Pubmed: 11758704.

32. O'Kelly CJ, Kulkarni AV, Austin PC, et al. The impact of therapeutic modality on outcomes following repair of ruptured intracranial aneurysms: an administrative data analysis. Clinical article. J Neurosurg. 2010; 113(4): 795-801, doi: 10.3171/2009.9.JNS081645, indexed in Pubmed: 19852537.

33. Rosengart AJ, Huo JD, Tolentino J, et al. Outcome in patients with subarachnoid hemorrhage treated with antiepileptic drugs. J Neurosurg. 2007; 107(2): 253-260, doi: 10.3171/JNS-07/08/0253, indexed in Pubmed: 17695377.

34. Rosengart AJ, Schultheiss KE, Tolentino J, et al. Prognostic factors for outcome in patients with aneurysmal subarachnoid hemorrhage. Stroke. 2007; 38(8): 2315-2321, doi: 10.1161/STROKEAHA.107.484360, indexed in Pubmed: 17569871.

35. Salem R, Vallée F, Dépret $F$, et al. Subarachnoid hemorrhage induces an early and reversible cardiac injury associated with catecholamine release: one-week follow-up study. Crit Care. 2014; 18(5): 558, doi: 10.1186/s13054-014-0558-1, indexed in Pubmed: 25358417.

36. Schmidt JM, Crimmins M, Lantigua $\mathrm{H}$, et al. Prolonged elevated heart rate is a risk factor for adverse cardiac events and poor outcome after subarachnoid hemorrhage. Neurocrit Care. 2014; 20(3): 390-398, doi: 10.1007/s12028-013-9909-z, indexed in Pubmed: 24043479.
37. Steiner T, Al-Shahi Salman R, Beer R, et al. European Stroke Organisation. European Stroke Organisation (ESO) guidelines for the management of spontaneous intracerebral hemorrhage. Int J Stroke. 2014; 9(7): 840-855, doi: 10.1111/ijs.12309, indexed in Pubmed: 25156220.

38. Steiner T, Juvela S, Unterberg A, et al. European Stroke Organization. European Stroke Organization guidelines for the management of intracranial aneurysms and subarachnoid haemorrhage. Cerebrovasc Dis. 2013; 35(2): 93-112, doi: 10.1159/000346087, indexed in Pubmed: 23406828.

39. Inamasu J, Sugimoto $\mathrm{K}$, Yamada $\mathrm{Y}$, et al. The role of norepinephrine and estradiol in the pathogenesis of cardiac wall motion abnormality associated with subarachnoid hemorrhage. Stroke. 2012; 43(7): 1897-1903, doi: 10.1161/STROKEAHA.111.646893, indexed in Pubmed: 22511007.

40. Tang C, Zhang TS, Zhou LF. Risk factors for rebleeding of aneurysmal subarachnoid hemorrhage: a meta-analysis. PLoS One. 2014; 9(6): e99536, doi: 10.1371/journal.pone.0099536, indexed in Pubmed: 24911172.

41. Taylor CL, Yuan Z, Selman WR, et al. Cerebral arterial aneurysm formation and rupture in 20,767 elderly patients: hypertension and other risk factors. J Neurosurg. 1995; 83(5): 812-819, doi: 10.3171/ jns.1995.83.5.0812, indexed in Pubmed: 7472548.

42. Toftdahl DB, Torp-Pedersen CT, Engel UH, et al. [Hypertension and left ventricular hypertrophy in patients with spontaneous subarachnoid hemorrhage]. Ugeskr Laeger. 1997; 159(10): 1434-1437, indexed in Pubmed: 9082630.

43. Tung PP, Olmsted E, Kopelnik A, et al. Plasma B-type natriuretic peptide levels are associated with early cardiac dysfunction after subarachnoid hemorrhage. Stroke. 2005; 36(7): 1567-1569, doi: 10.1161/01.STR.0000170699.59783.d6, indexed in Pubmed: 15947264.

44. Bilt Iv, Hasan D, Brink Rv, et al. Cardiac dysfunction after aneurysmal subarachnoid hemorrhage: Relationship with outcome. Neurology. 2013; 82(4): 351-358, doi: 10.1212/wnl.0000000000000057.

45. Wartenberg KE, Schmidt JM, Claassen J, et al. Impact of medical complications on outcome after subarachnoid hemorrhage. Crit Care Med. 2006; 34(3): 617-23; quiz 624, doi: 10.1097/01. ccm.0000201903.46435.35, indexed in Pubmed: 16521258.

46. Zhang L, Zhang B, Qi S. Impact of echocardiographic wall motion abnormality and cardiac biomarker elevation on outcome after subarachnoid hemorrhage: a meta-analysis. Neurosurg Rev. 2018 [Epub ahead of print], doi: 10.1007/s10143-018-0985-6, indexed in Pubmed: 29804158.

47. Zhao B, Zhao Y, Tan X, et al. Factors and outcomes associated with ultra-early surgery for poor-grade aneurysmal subarachnoid haemorrhage: a multicentre retrospective analysis. BMJ Open. 2015; 5(4): e007410, doi: 10.1136/bmjopen-2014-007410, indexed in Pubmed: 25877280.

48. Zheng J, Xu R, Liu G, et al. Effect of premorbid hypertension control on outcome of patients with aneurysmal subarachnoid hemorrhage. Acta Neurochir (Wien). 2018; 160(12): 2401-2407, doi: 10.1007/ s00701-018-3699-1, indexed in Pubmed: 30315363. 